\title{
A qualitative study on the attitudes of patients with gastrointestinal cancer toward being informed of the truth
}

This article was published in the following Dove Press journal: Patient Preference and Adherence

\author{
Feimin Yang' \\ Qian Zhang' \\ Wei Kong' \\ Hongdan Shen' \\ Jing Lu' \\ Xiaolong $\mathrm{Ge}^{\prime}$ \\ Yiyu Zhuang ${ }^{2}$
}

'Department of General Surgery, Sir Run Run Shaw Hospital, School of Medicine, Zhejiang University, Hangzhou, Zhejiang 310016, China; ${ }^{2}$ Nursing Department, Sir Run Run Shaw Hospital, School of Medicine, Zhejiang University, Hangzhou,

Zhejiang 310016, China
Correspondence: Yiyu Zhuang Nursing Department, Sir Run Run Shaw Hospital, School of Medicine, Zhejiang University, 3 East Qingchun Road, Hangzhou, Zhejiang 310016 , China Tel +86 I358870 8076

Fax +86 57I 86006616

Email 3196048@zju.edu.cn
Objective: The aim of this study is to investigate the attitudes of hospitalized patients with gastrointestinal cancer toward being informed of the truth and to provide references for informing patients of their gastrointestinal cancer diagnosis.

Methods: Nine patients with gastrointestinal cancer were selected for this study by using a purposive sampling technique from a general surgery ward in a tertiary-level general hospital in Zhejiang Province from June 2016 to October 2016. Semi-structured, in-depth interviews were conducted, and the descriptive phenomenological method (developed by Amedeo Giorgi) was used to analyze the interview data.

Results: Five themes were developed through reading, analysis, reflection, and classification of the data: Theme 1, guessing the diagnosis of gastrointestinal cancer before being informed of the truth; Theme 2, eagerness to know the diagnosis results; Theme 3, expectations related to beginning treatment for cancer; Theme 4, stress and anxiety during treatment; and Theme 5, providing patients with hope and optimism at the early diagnosis stage.

Conclusion: Patients have a strong desire to survive and can confidently confront their gastrointestinal cancer diagnosis. Medical staff should carefully select the appropriate time to inform patients of their diagnosis by evaluating their attitudes toward being informed, thereby actively meeting patients' needs for information and treatment.

Keywords: patient with gastrointestinal cancer, disclosure of diagnosis, qualitative study

\section{Introduction}

Each year, 1.52 million new cancer cases occur in China, and the 10-year growth rate of malignant cancers is $31 \%$. The incidence of cancer in China accounts for $21.8 \%$ of the global cancer incidence. ${ }^{1}$ The incidence and mortality rate of gastrointestinal cancer are high worldwide, and benign cancers account for only $2 \%$ of this rate. Stomach cancer, liver cancer, colorectal cancer, and esophageal cancer are common types of gastrointestinal cancers. The disclosure of a gastrointestinal cancer diagnosis involves both legal and ethical issues. Medical staff faces a dilemma when disclosing a diagnosis of gastrointestinal cancers to patients.

\section{The methods used by medical staff to disclose a cancer diagnosis to patients}

In developed countries such as the US, $90 \%$ of physicians will directly inform patients of a cancer diagnosis. Medical staff and the families of patients reach a consensus on disclosing a diagnosis to the patient. However, according to traditional culture and fundamental realities of the country, medical staff in China mainly adopt a protective 
route in the disclosure of a cancer diagnosis; that is, they try not to inform patients of the diagnosis. Some studies have shown that disclosure of a cancer diagnosis to patients with a low tolerance to psychological distress or to those with an introverted personality may increase unnecessary fear and rapidly make the patient's condition worse. ${ }^{2}$ Even when the patient is in the late stage of cancer, medical staff still prefer to withhold information from patients.

With the development of medical research and medical technology, the recovery rate of cancer has significantly improved. By gaining knowledge and psychological guidance, increasing numbers of informed patients have been able to cooperate with the medical staff during treatment with an optimistic and active attitude. At present, the principle of "whether to tell patients the truth" is gradually being switched to "how to tell patients the truth". Studies have shown that different notification methods may have different impacts on the quality of life of patients with cancer, both mentally and physically, and may even affect their life span. ${ }^{3}$ Therefore, studies have been conducted on who should inform patients, when to inform patients, and what information should be given and how it should be given in order to further establish guidelines for informing patients of their cancer diagnosis. $^{4}$

\section{Attitudes of patients with cancer toward being informed of the diagnosis}

Many investigations have been conducted on patient's informed consent worldwide. The results have shown that most patients with cancer are willing to know the truth of their diagnosis. ${ }^{4-7}$ In a study, 84 patients with cancer were interviewed. Among them, $92.9 \%$ patients wished to be informed of the diagnosis, $54.7 \%$ considered being informed helpful for treatment, $31 \%$ thought that being informed could help them relax, and $14.3 \%$ believed that being informed is helpful to ensure better job and life arrangements. Studies in China have shown that patients who are not notified regarding the diagnosis are more anxious and depressed than those who are informed. ${ }^{8}$ International studies have also stated that informing patients of their true diagnosis did not lead to increased anxiety and depression, and their quality of life did not decline. ${ }^{9}$ The above results indicate that for most patients with cancer, not telling them of their diagnosis is not consistent with their wishes. With the development of medical technologies, the life expectancy of patients with cancer has been prolonged, and the chance of making a full recovery is also higher. Particularly, in recent years, groups such as cancer patient clubs, cancer rehabilitation salons, and other such groups have been organized to help patients fight cancer together, which alleviates their fears and enhances their tolerance to stress, thus making them more willing to be informed.

Some surveys have suggested that patients with cancer want to know their diagnosis and prognosis, but because of the intervention from family members, the percentage of informed patients is low. ${ }^{10-12}$ International studies have shown that patients with cancer believe that they should be informed of the diagnosis rather than their family members. ${ }^{13}$ A survey of 228 family members of patients with cancer showed that $19.7 \%$ of them preferred to keep the information strictly confidential from the patient and $65.4 \%$ chose to keep it undisclosed for a short period. Additionally, significant differences were found in education levels and age groups of those choosing confidentiality. ${ }^{14}$ These results were consistent with those of the study by Sun et al, ${ }^{15}$ where more people held a negative attitude toward informing the patient of the diagnosis. In China, patients often grant the right of informed consent to their family members or caregivers, and eventually, the patient's rights have become the right of their family members. ${ }^{16}$ Although this approach can solve the problem between the patient's right to informed consent and protecting the patient from being distressed, patients lose their right of being informed of the truth. Therefore, the attitude of the patient's family toward informing the patient is crucial in these cases.

\section{Factors that affect informing the patients of the diagnosis}

Clinically, it is difficult to inform patients of a diagnosis of cancer because of the patient's own fear of cancer, the attitudes of the family and physicians toward informed consent, and the medical risk management. ${ }^{17}$ Studies on the attitudes of patients toward being informed of a cancer diagnosis showed that several factors affect their attitudes, including age, occupation, education level, marriage status, bereavement experience, financial status, emergency response ability, and time at which they were informed. ${ }^{18}$ Older patients who are notified in a shorter amount of time, have a richer life experience, and show an eagerness to learn more about the disease usually can tolerate more stress. Patients with higher education levels, better financial status, greater access to information, a stronger attitude toward self-protection, better adaptive ability, and an active attitude toward treatment usually require a higher level and more comprehensive information about their illness. Farmers and married or widowed patients often want to understand more about the 
causes, treatments, and prognosis of cancer. Farmers are more concerned about the cost of treatment, while married patients are more concerned about the impact on their family; furthermore, those who have experienced bereavement are more able to face the distress. Surveys have also shown that patients with a younger age, an extroverted personality, a higher education level, and a good job are more willing to be informed of the diagnosis at an early stage. ${ }^{19}$

Patients' attitudes toward being informed of the truth play a crucial role in the choice of how to effectively disclose their diagnosis to them. By adopting a qualitative phenomenological research approach, in this study, we conducted in-depth interviews with informed patients with gastrointestinal cancer to understand the psychological changes they underwent before and after being informed, whether or not they wanted to be informed, and what type of support they need from family and medical staff. The results of this study will help clinical staff to disclose the diagnosis to patients according to the patients' attitudes toward being informed of the truth.

\section{Materials and methods Clinical materials}

A purposive sampling technique was used to select patients with gastrointestinal cancer for the study from a general surgery ward in a third-tier class-A hospital in Zhejiang Province between June 2016 and October 2016. The following were the inclusion criteria for this study: age 18 years or above; education level of elementary school or higher; no communication disorders or mental illness; a pathological diagnosis of cancer; a full understanding of their own illness; undergoing radiotherapy and chemotherapy after surgery; and voluntary participation. The sample size was determined by data saturation, meaning that the data of some interviewees reappeared, and no new themes appeared while analyzing their data. There were nine patients who met the inclusion criteria, and five patients refused to participate in the study. Finally, nine patients were enrolled in the final interviews; these participants differed in terms of age, education level, occupation, financial status, marriage and family status, and the stage of treatment.

\section{Methods \\ Ethical issues}

Before the interview, the interviewees were informed in detail regarding the purpose, methods, content, and confidentiality of the study. The analysis of the results and the writing of the paper were coded and carried out anonymously. Written informed consent forms were signed by all interviewees. This study was approved by the ethics committee of Sir Run Run Shaw Hospital, School of Medicine, Zhejiang University, and this study was conducted in accordance with the Declaration of Helsinki.

\section{Data collection}

The final interview questions were established to include questions about the general information of patients, such as sex, age, personality traits, education level, occupation, social behavior, financial status, marriage and family status, cancer location, and stage of treatment.

\section{Preparation of interview questions}

Interview questions were initially prepared using the literature and were then discussed and revised by one senior surgical nurse, one psychologist, and one senior oncology nurse. Preinterviews with two eligible patients were conducted using the prepared interview questions, and the results were used for the further modification of questions. The final interview questions were then established and included questions such as "Who will make the decision when you encounter an issue?", "Do you usually prefer to stay alone?", "How did you learn about your illness?", "How did you feel after you were informed of the diagnosis results?", "Would you like to be informed of the truth?", "By whom and how would you like to be informed?", and "What type of support would you like to have?".

\section{Data collection methods}

Face-to-face, semi-structured, and in-depth interviews were used to collect data. All interviews were conducted in a quiet classroom in the wards, and interview questions were used as the framework. During the interview, no inductive questions were asked, and video recordings were made for the observation of nonverbal behaviors and body movement changes. Patients could be accompanied by a close family member to allow them to be more authentic. Each interview lasted 30-40 minutes.

\section{Data analysis}

The data analysis was conducted by the interviewer and another researcher within 24 hours of the interview. First, the recordings were transcribed and entered into a computer along with the data submitted on paper forms. Second, to ensure the accuracy, the transcripts were read carefully while playing the recordings repeatedly. Patient names were replaced by letters (A, B, C, etc.) to protect patient confidentiality during this 
process. Last, the data were analyzed using the descriptive phenomenological method (developed by Amedeo Giorgi), which included the following six steps. Step 1: Read the transcripts of the first three interviews repeatedly to identify possible themes. It is suggested to create a coding system for content analysis. Step 2: Read the rest of the transcripts repeatedly and further refine the themes according to the coding system. Two data analysts should discuss and refer to the original data when problems arise; reanalyze and revise the coding system. Step 3: Further refine the themes and categories. Themes seemingly unrelated to the research issues also need to be carefully categorized. Step 4: Preliminarily define each theme and category to understand the phenomenon under study and the relationships between and among various elements of the phenomenon. Step 5: Go through all four steps above and review the resulting data and the study objectives for content validity. Step 6: Through an analysis of the above data, a structured description and interpretation of the phenomenon can be formed.

\section{Results}

Study population and baseline characteristics

During the study period, nine patients were enrolled. Among them, two were female and seven were male. The mean age was $57.4 \pm 5.9$ years. Three patients were diagnosed with colon cancer, three were diagnosed with gastric cancer, and the others were diagnosed with liver cancer. Details of the patient information are provided in Table 1.

\section{Theme I: Patients guessed that they might have cancer before being informed of the diagnosis}

Their guess was based on the change in attitudes and behaviors of family members and doctors. Six out of nine interviewees guessed that they may be diagnosed with cancer. Among them, two patients guessed the cancer diagnosis while the doctors came to check on them on the second day after

Table I Characteristics of the study population

\begin{tabular}{|c|c|c|c|c|c|c|c|c|c|c|}
\hline Patients & Sex & Age & Education & Personality & $\begin{array}{l}\text { Social } \\
\text { behavior }\end{array}$ & Occupation & $\begin{array}{l}\text { Financial } \\
\text { status }\end{array}$ & Family & $\begin{array}{l}\text { Tumor } \\
\text { location }\end{array}$ & Treatment \\
\hline A & $M$ & 57 & HS & Outgoing & Assertive & Worker & General & $\begin{array}{l}\text { Married } \\
\text { three girls }\end{array}$ & Colon & $\begin{array}{l}\text { Second round of } \\
\text { chemotherapy } \\
\text { after surgery }\end{array}$ \\
\hline B & $M$ & 59 & JMS & Outgoing & Assertive & Self-employed & Bad & $\begin{array}{l}\text { Married } \\
\text { one son }\end{array}$ & Liver & $\begin{array}{l}\text { Recurrence after } \\
\text { chemotherapy } \\
\text { after second } \\
\text { surgery }\end{array}$ \\
\hline C & $M$ & 63 & JMS & Outgoing & Assertive & Self-employed & $\mathrm{Bad}$ & $\begin{array}{l}\text { Married } \\
\text { one son }\end{array}$ & Colon & $\begin{array}{l}\text { Eighth round of } \\
\text { chemotherapy } \\
\text { after surgery }\end{array}$ \\
\hline D & $M$ & 69 & ES & Outgoing & Assertive & Farmer & Better & $\begin{array}{l}\text { Married } \\
\text { two sons, one girl }\end{array}$ & Stomach & $\begin{array}{l}\text { Third round of } \\
\text { chemotherapy } \\
\text { after surgery }\end{array}$ \\
\hline$E$ & $M$ & 75 & ES & Outgoing & Indecisive & Farmer & General & $\begin{array}{l}\text { Married } \\
\text { two sons, two } \\
\text { girls }\end{array}$ & Stomach & $\begin{array}{l}\text { Eighth round of } \\
\text { chemotherapy } \\
\text { after surgery }\end{array}$ \\
\hline $\mathrm{F}$ & $M$ & 71 & ES & Shy & Assertive & Farmer & General & $\begin{array}{l}\text { Married } \\
\text { two sons, one girl }\end{array}$ & Liver & $\begin{array}{l}\text { Second round of } \\
\text { chemotherapy } \\
\text { after surgery }\end{array}$ \\
\hline G & $\mathrm{F}$ & 28 & C & Outgoing & Assertive & Travel agent & General & $\begin{array}{l}\text { Married } \\
\text { one son }\end{array}$ & Colon & $\begin{array}{l}\text { Eighth round of } \\
\text { chemotherapy } \\
\text { after surgery }\end{array}$ \\
\hline $\mathrm{H}$ & $M$ & 28 & C & Shy & Indecisive & Handyman & General & Unmarried & Liver & $\begin{array}{l}\text { Recurrence } \\
\text { I year after } \\
\text { surgery }\end{array}$ \\
\hline I & $\mathrm{F}$ & 67 & ES & Shy & Assertive & Worker & General & $\begin{array}{l}\text { Married } \\
\text { one son }\end{array}$ & Stomach & $\begin{array}{l}\text { First round of } \\
\text { chemotherapy } \\
\text { after surgery }\end{array}$ \\
\hline
\end{tabular}

Abbreviations: C, college; ES, elementary school; F, female; HS, high school; JMS, junior high school; M, male. 
surgery; one patient guessed the results after being visited by many family members; one patient guessed the results after colonoscopy; two patients guessed the diagnosis after being treated with interventional radiology; and three patients guessed the diagnosis during their first chemotherapy. Case A: "My family came to see me often after the surgery. However, the doctor would not tell me my diagnosis even when I asked what was wrong with me". Case C: "Neither my family nor the doctor told me the diagnosis results until long after my colonoscopy. However, my wife was called to the doctor's office the day after my colonoscopy. Therefore, I thought I might have cancer". Case G: "When I was undergoing a thoracentesis, the doctor looked surprised and expressed sympathy, which made me assume that I must have a serious disease".

\section{Theme 2: Patients are eager to know their diagnosis}

Patients are more sensitive in the early diagnosis of illness. They are eager to know their diagnosis and hope to be informed of the truth so that they can make appropriate provisions related to their job, family life, and treatment plan. Six out of nine interviewees proactively asked their doctor or their family about their diagnosis. Three patients had questions, but did not take the initiative to ask. Case A: "I really wanted to know if I had cancer after the surgery. Therefore, I told the doctor that I knew I may have cancer and that I am able to face the truth, so please tell me the diagnosis". Case D: "I noticed that my son was called to the doctor's office after my gastroscopy. Upon leaving the office, his eyes appeared red, like he had been crying. Therefore, I asked him, what kind of illness do I have?" Case G: "I think the doctor had talked to my husband about my diagnosis after my thoracentesis. However, my husband was still not very clear and not very sure about it. I was angry about it. Therefore, I asked the doctor while he was on duty one day. I told him that I will think I am dying if he does not tell me know my diagnosis, so please tell me the truth".

\section{Theme 3: Patients look forward to treatment after knowing the diagnosis}

The interviewees differed regarding their financial and family situations. However, after being informed of their diagnosis, eight patients remained confident, were actively involved in the treatment of the disease, and looked forward to recover from the disease. One patient thought that he could do nothing but follow the doctor's arrangements. Case A: "I guess I have cancer. I'm fine with it and still have remained calm after being informed of my cancer diagnosis. I'll try my best to do what I can. But if it is difficult to get well, or it turns out to be very painful, I'll accept it as my destiny". Case B: "I knew I had gastrointestinal cancers; I'm fine with the diagnosis since it has already happened. There is no need to hide the truth from me. I wanted to be informed of my diagnosis and discuss my treatment plan with the doctor". Case G: "I urged the doctor to tell me the truth about my illness. I wanted to receive gastrointestinal cancer treatments, whatever they are, since I have a young son at home waiting for me to recover. Immediately after I was informed of my diagnosis, I started to do some research about this illness, asked around, and discussed my treatment plan with the doctors".

\section{Theme 4: Patients experience stress during the gastrointestinal cancer treatment process}

The pain experienced during the gastrointestinal cancer treatment process is the greatest stressor for patients, which might cause them to terminate treatment. In addition, other factors, such as financial burden, recurrence, and family members' excessive concerns, can create added pressure. Cases E, G, H, and I: "The pain during the treatment is quite uncomfortable. As long as the pain is under control, patients feel comfortable enough to continue treatment. If the pain becomes uncontrollable, patients may want to discontinue treatment". Cases B, $\mathrm{C}$, and I: "The financial pressure is so great that the patients have to borrow money to pay for treatment". Cases B, G, and I: "Recurrence and metastasis make the patients feel upset and increase their pain level". Case A: "It makes me more nervous when my family is overconcerned". Case G: "I have no appetite, but my family members always force me to eat. I don't think they understand my pain".

\section{Theme 5:After the disease is diagnosed, patients want to be informed with hope and optimism}

Telling patients their diagnosis has a profound effect on their emotional well-being and psychological stress level. It is important to present positive features while telling patients the truth; in this way, patients can face their treatment with a positive attitude. Of the nine interviewees, four expected to be informed by their doctor, one preferred to be informed by both their doctor and family together, and four wanted to be informed by family members. Six out of the nine interviewees wanted to be informed at the stage of initial diagnosis, while the other three wanted to be informed after the diagnosis was confirmed surgically. Case F: "A doctor from interventional 
radiology told me that there was no effective treatment in my case, and the only thing we could do was to control it, which left me scared for the entire day. It is not good to break bad news such as this directly, which makes patients even more nervous". Case A: "My doctor and family did not tell me the diagnosis, but I knew it. I went to the bookstore and got a reference book there. The book stated that the recurrence was low and the survival rate was high if the disease could be controlled for 3-5 years. I don't think that it was necessary to hide the truth from me". Case G: "The doctor told me that I had only 3 to 6 months to live, and I was broken down by the news, sad and mad. I couldn't accept the diagnosis and refused any treatment. After I was referred to another doctor, Dr Fang, I was told some other positive news. Now, I can actively accept the diagnosis and hope to take treatment as soon as possible. I'm happy that there have been good results after my first round of chemotherapy".

\section{Discussion}

\section{Studies on strategies of informing patients with gastrointestinal cancer}

Establishing a scientific, patient-centered notification and evaluation system will achieve the best effect of telling patients their diagnosis. When the family is worried that the patient may be fearful and unable to confront the diagnosis of gastrointestinal cancer, medical staff should talk with the family first to learn about the patient's personality and the possibility of emotional changes after being informed of the diagnosis in order to determine whether or not the family is overestimating the patient's negative emotions. Medical staff should explain to the family the general psychological changes after being informed and the right way to support the patient, as well as encourage the family to have a positive attitude toward the diagnosis. Changing the attitude of the family toward the gastrointestinal cancer diagnosis is the first thing to do before informing patients of the diagnosis. When considering telling these patients the truth, we first need to understand patients' attitudes toward being informed, their physical and psychological situations, and their personalities and characters. Then, we can determine how to inform them and the extent to which they should be informed, which is consistent with the study by Zeng et al. ${ }^{20}$ There are many different ways to disclose a gastrointestinal cancer diagnosis to a patient, such as giving hints incrementally, presenting positive features, giving patients hope and optimism, encouraging their confidence to fight the disease, explaining the possible side effects during treatment, and showing them successful examples, all of which can help patients take an active attitude toward treatment.

\section{Multidisciplinary team support and psychological assistance}

Psychological assistance can help patients relieve symptoms such as suspicion, anxiety, depression, and pressure and improve their confidence and quality of life. Some studies have shown that although patients have depression, anxiety, somatization, other psychological symptoms, and decreased self-efficacy, they have not completely lost their confidence and hope for treatment. ${ }^{21,22}$ Other studies have also shown that patients who are not informed of their own diagnosis are more likely to have anxiety and depression than those who are informed. ${ }^{23}$ Through psychological nurses conducting evaluations on the degree of patients' anxiety, level of confidence in life, and risk of self-harm, we can understand more about patients' personalities, behaviors and attitudes toward being informed of their true diagnosis. Therefore, we can develop a treatment plan involving both medical and psychological assistance, which enables patients to build confidence to fight the disease. In addition, the families of patients with gastrointestinal cancer are under tremendous pressure from having to hide the truth, and their psychological states should not be ignored. Medical staff can improve the families' understanding by appropriately providing them with new information regarding gastrointestinal cancer treatment progress and prospects. Expressing empathy can also help relieve the pressure faced by the families.

\section{Providing continuity of care and medical counseling from the hospital}

Continuity of care is an orderly, coordinated, and ongoing rehabilitation service provided by different or the same health care provider to meet the actual needs of patients after discharge from the hospital. ${ }^{24} \mathrm{~A}$ high financial cost and the side effects of gastrointestinal cancer treatment, such as pain, nausea, and vomiting during radiotherapy and chemotherapy, impose a great pressure on most of these patients. Therefore, during the treatment process, pain evaluation and management are very important in clinical practice. Inviting a pain specialist to help patients effectively manage their pain and establishing a follow-up system to understand patients' pain-control situations can help improve patients' pain perception and quality of life. In addition, these patients have an urgent need for dietary guidance during the treatment process and after discharge, such as the types of food allowed, the serving amounts, and cooking methods. A nutritionist can 
provide personalized nutritional education and ongoing monitoring and evaluation for patients with gastrointestinal cancer. The continuity of care service provided by hospitals not only enables the patient to receive professional health care over time but also enables them to feel care and warmth from our society.

\section{Conclusion}

Disclosing the diagnosis of gastrointestinal cancers to patients has become a large issue faced by health care providers today. To the best of our knowledge, there are few studies focusing on this topic. Our study conducted interviews with patients with gastrointestinal cancer to understand their attitudes toward being informed of their diagnosis. This qualitative study was conducted in our hospital, and the interview data show that most patients are eager to know their diagnosis, expect to receive medical treatment, and want to be informed with hope and optimism. However, there are still some limitations in our study. First, more enrolled patients will be needed to verify our result. Second, the patients enrolled in our study had already known about their state of disease, and our study was a retrospective observational analysis. Thus, it might be not reveal the real feeling of patients during the interview. Last but not least, the expectation of illness course of enrolled patients was not analyzed in detail, and more information is needed in the future study. Therefore, future studies should focus on strategies of disclosing the gastrointestinal cancer diagnosis to patients to improve their physical and psychological well-being.

\section{Acknowledgments}

The authors gratefully acknowledge all the investigators for their contributions to the trial, as well as Bin Chen, who provided medical writing assistance. The study was supported by a grant from the National Natural Science Foundation of China (81800474).

\section{Disclosure}

The authors report no conflicts of interest in this work.

\section{References}

1. Gao T, Li C, Liang X. A comparison of cancer incidence in China and around the world. China Cancer. 2016;201(6):409-414.

2. Wang ZH, Wang YH. Common types of psychological responses and psychological care for cancer patients. Occup Health. 2003;19(12): 183-184.
3. Zou JJ, Gao Y, Cao CW. Preliminary study on the impact of being informed of diagnosis on quality of life and mood of cancer patients. Cancer. 2004;24(5):490-493.

4. Zeng TY, Zhang Q, Yang XM. Investigation and research on disclosing diagnosis to cancer patients. Chin Nur Res. 2008;12(12):3126-3128.

5. Xie J, Zhou Q. Investigation and analysis of the informed right of patients with malignancy. J Modern Oncol. 2007;15(7):1048-1049.

6. Lin H, Qin J. Investigations on the informed right of cancer patients. Chin J Gerontol. 2010;8(20):2355-2356.

7. Farhat F, Othman A, El Baba G, Kattan J. Revealing a cancer diagnosis to patients: attitudes of patients, families, friends, nurses, and physicians in Lebanon-results of a cross-sectional study. Curr Oncol. 2015; 22(4):264-227.

8. Zhao XX, Liu ZW, Guo JB. Analysis of depression and anxiety of terminal cancer patients toward being informed diagnosis results. J Mod Oncol. 2013;12:2815-2817.

9. Lazzaniga LF, Maroni D, Bianchi E, et al. Anxiety, depression and informed consent of patient referred to a radiotherapy department. Tumori. 2003;89(2):176-182.

10. Zeng TY, Zhou M, Feng LJ, et al. Investigation on patients' attitude toward being informed the diagnosis of malignant cancer. Chin Nurs Res. 2008;22(6):1522-1523.

11. Zeng TY, Li QL, Wu ML, et al. Analysis of the factors affecting cancer patients' attitude toward being informed the truth. Chin Nurs Res. 2009; 8:670-672.

12. Meng L, Li QL, Zeng TY. Influencing factor analysis of medical staff's strategy during evaluate and select the way to inform cancer patients. J Nurs Sci. 2009;24(1):9-11.

13. Yun YH, Lee CG, Kim SY, et al. The attitudes of cancer patients and their families toward the disclosure of terminal illness. J Clin Oncol. 2004; 22(2):307-314.

14. Zhang QX. Investigations on the attitudes of Cancer Patients' family toward protective care \& Analysis of causes. Chin Nurs Res. 2007; 21(5):1170-1171.

15. Sun YQ, Li Z, Sun BF, Chang LR. Analysis on attitudes of cancer patients' family toward telling patients the truth and Analysis on factors affecting their attitudes. Chin J Nurs. 2007;42(6):556-559.

16. Xs M. Implementation of informed consent for clinic treatment in China. Med Philos. 2003;24(1):1-4.

17. Jiang LJ, Yuan JB, Yin XX. Strategies and analysis of disclosing cancer patients the truth. Chin Health Serv Manage. 2016;10:798-799.

18. Zhan HP, Lu P, Hong M. Investigation and analysis of cancer patients' demand in being informed of diagnosis. Nurs Prac and Res. 2015; 12(11):100-102.

19. Huang JY, Zhong JH, Zhang XL. Pros and Cons of protective care in cancer treatment. Med Inf. 2013;10(26):190.

20. Zeng TY. [Studies on cancer notification strategies. Huazhong University of Science and Technology]. 2008. Chinese.

21. Harrington CB, Hansen JA, Moskowitz M, Todd BL, Feuerstein M. It's not over when it's over: long-term symptoms in cancer survivors - a systematic review. Int J Psychiatry Med. 2010;40(2):163-181.

22. Chen XH, Mao GB. Analysis of end-of-life care for terminal cancer patients in acute care hospitals. Prac J Card Cereb Pneumal Vasc Dis. 2011;19(11):1934.

23. Zhao XX, Liu ZW, Guo JB. Analysis of depression and anxiety of terminal cancer patients toward being informed diagnosis results. J Mod Oncol. 2013;12:2815-2817.

24. King M, Jones L, Mccarthy O, et al. Development and pilot evaluation of a complex intervention to improve experienced continuity of care in patients with cancer. Br J Cancer. 2009;100(2):274-280. 


\section{Publish your work in this journal}

Patient Preference and Adherence is an international, peer-reviewed, open access journal that focuses on the growing importance of patient preference and adherence throughout the therapeutic continuum. Patient satisfaction, acceptability, quality of life, compliance, persistence and their role in developing new therapeutic modalities and compounds to optimize

clinical outcomes for existing disease states are major areas of interest for the journal. This journal has been accepted for indexing on PubMed Central. The manuscript management system is completely online and includes a very quick and fair peer-review system, which is all easy to use. Visit http://www. dovepress.com/testimonials.php to read real quotes from published authors.

Submit your manuscript here: http://www.dovepress.com/patient-preference-and-adherence-journal 